\title{
Community intervention in urban areas: $A$ youth driven initiative
}

\section{Claudia P Carvalho}

Centre for Social Studies, University of Coimbra, Portugal

\begin{abstract}
This paper aims to reflect on the results of the project Community Intervention in Urban Areas: a youth driven initiative. This project envisioned the development of a Transnational Seminar that gave origin to the development of youth arts intervention projects and to the elaboration of the document "Youth Policies for Urban Neighborhoods". The project started from the youth's reflection on the physical, social, economic, and cultural degradation of specific spaces/territories and communities in Portugal, Italy, the Netherlands, and Belgium (spaces in ruins, non-places and other abandoned areas), exploring these territories as spaces for transformation and future renovation. The idea is to explore the ways youth may contribute to the transformation of these spaces, therefore enhancing their civic knowledge, capacity to intervene and influence policy and research under this theme. We wish to explore the role of younger generations, and youth in particular, through a change of paradigm. That is, by developing alternatives of intervention, through Participant Action Research and through the exploration of its connections with artistic practice and the cultural field in general. We hope this approach can influence local, national and European youth education policies and enhance different approaches to research in general.
\end{abstract}

\section{Keywords}

Artistic practice, community intervention, action research, youth development, degraded urban areas

\section{Introduction: The importance of youth involvement in civic engagement in European Cities in transition}

Community Intervention in Urban Areas: a youth driven initiative (CIUA) is a project funded by the former Youth in Action Program (actual ERASMUS+),

Corresponding author:

Claudia P Carvalho, Centre for Social Studies, Colégio de S. Jerónimo, Largo D. Dinis, Apartado 3087o, Coimbra 3000-995, Portugal.

Email: claudiacarvalho@ces.uc.pt 
a program from The Directorate General for Education and Culture (DG-EAC). This initiative grew out of the work that the theater company $\mathrm{O}$ Teatrão (Coimbra, Portugal) has been doing, through an extensive arts education project with a special focus on the relationship between youth citizenship and artistic practice. The project's specific goal is to create - via a network of youth intervention and collaboration with politicians, experts in youth policies and artists who are connected with local policies and activities - artistic interventions in the different cities involved as partners. This project was developed in partnership with $\mathrm{O}$ Teatrão (Coimbra, Portugal), the Associazione Marchigiana Ativitá Teatrali-AMAT (Ancona, Italy), the HETPALEIS (Antwerp, Belgium) and the Theatermijn (Zaanstad, the Netherlands). What follows is an explanation of CIUA processes and methodologies, to bring to the forefront of the discussion how this project, and the use of participatory artistic approaches may positively contribute to the Participative Action Research field.

In recent years, growing importance has been given to the incorporation of artistic methodologies in practices of action research (Fisher \& Phelps, 2006; Lykes, 2001). The current paper adds to this field by sharing a project that uses performance art as a vehicle for civic engagement, enriching the Participatory Action Research field (Reason \& Bradbury, 2001; Strand, Marullo, Cutforth, Stoecker, \& Donohue, 2003) and bringing added value to the already produced knowledge on the matter (Beyes \& Steyaert, 2011; Cole, Neilsen, Knowles, \& Luciani, 2004). Civic engagement among youth cannot be learned only theoretically, but comes as a result of involvement in community-based projects (Schiller, 2013). Jessica Schiller (2013) refers to a "civic knowledge gap" as one of the most important variables that tend to negatively influence the effectiveness of contemporary democracy (Lutkis \& Weiss, 2007). There are many activities and strategies that may enhance civic knowledge, including the establishment of connections with the surrounding community by incentivizing awareness and knowledge of local projects and the partners involved in specific intervention projects (Hess, 2009; McIntosh \& Munoz, 2009; Westheimer \& Kahne, 2004).

Recently, an ongoing concern has emerged about how to create civic competences within young people and the community at large (Coe, Goicolea, Hurtig, \& San Sebastian, 2015; Quintelier, 2013). All studies that focus on low-income and urban youth find positive results stemming from engagement in civic activities (Mediratta, 2007; Mediratta \& Fruchter, 2001; Warren, 2005; Zachary \& Olatoye, 2001) and identify several problems that may remain difficult to resolve if civic competences are not developed (Levine \& Yourniss, 2006). Atypical interventions in urban public space create conditions for the generation of "radical social practices" (Kwon, 2004), which demand critical thinking about the reason for specific arts intervention initiatives and how they can be associated with participatory methodologies (Degarrod, 2013; Holtby, Klein, Cook, \& Travers, 2015).

The examples from different countries can enhance new approaches to the process of knowledge generation (Brydon-Miller, Antal, Friedman, \& Wicks, 2011). In Denmark, theater is being used to communicate experiences that have difficulty 
reaching the mainstream public agenda (Tofteng \& Husted, 2011). In Bangladesh, socially oriented theatrical forms are leading to engagement in societal discussions (Guharthakurta, 2008). In Italy, visual methods have proven effective in interpreting the needs of local citizens (Arcidiacono, Grimaldi, Di Martino, \& Procentese, 2016). Moreover, community arts projects are currently being explored in several European countries like Belgium (with the Music production organization $M E T-X$ ) and the Netherlands (with the community art project called Zina). These projects use artistic practice methods in combination with social sciences documentary approaches to produce social transformation (De Bruyne \& Gielen, 2011). Very recent experiments in Germany explore how a Time Window app tool-an application for cell phones created by young people - can digitally create the possibility of overlapping old photographs with actual visited sites (Forster \& Metzger, 2015). In a similar vein, the Maraya creates site-based systems that explore the possibilities of engagement through artistically designed forms (Lowry, Levin, \& Tsang, 2015). In this specific case, the artists and the researchers have developed a project that uses digital techniques to create billboard projects, alternative tours of cities, based on alternative mapping. In these contexts, spatial and pedagogical projects are created to amplify the notion of space and develop the social interventionist character of art making. Through the possible connections between education, civic society and artistic, and cultural interventions, CIUA wishes to generate reflective thinking and proposals of intervention in the field, offered from the perspective of young people.

\section{Methodology}

For the last two years O Teatrão had been seeking ways in which youth can contribute to transformation of urban spaces through experimental artistic intervention. In this project, youth from four countries (Portugal, Italy, Belgium and the Netherlands) were brought together to discuss, reflect, and propose solutions for the problems they identified in their own communities. The youth subsequently carried out exploratory projects in their respective countries. CIUA was designed as an integrated approach between the groups from the different countries. I now describe CIUA's three phases: preparation, implementation, and evaluation/ generation of final products including the specific methodologies that were developed for each phase.

\section{Preparation phase}

At the individual project level we built on the "Question Campaign Methodology" (QCM) in the various communities of the different countries. QCM (created by Ceasar McDowell and the organization Engage the Power) provides an opportunity for people who seldom participate in democratic processes to join in creating and sharing knowledge and action. The goal of QCM is to create an environment in which everyone (all members of a specific community) has an opportunity to raise 
what they believe are the most pressing questions for their own community, neighborhood, or city. Thus, each citizen participates in the definition of critical issues for their own communities independent of issues appointed by a group of representatives (McDowell \& Otero, 2011). QCM is based on a structured number of steps: commitment to values, question identification, design and production of social media, community outreach, question selection and public engagement in addressing questions we had adapted to the context of intervention in each country.

In the preparation phase (that took place from May to June 2014) we asked the youth to define a specific space/theme in which they would like to focus their intervention. Secondly, the youth identified a set of questions per theme exploring artistic/cultural practice that were relevant to the theme. The locales for these interventions ranged from abandoned downtown urban areas to small, urban-rural areas, to historic urban areas. Themes included youth migration, urban areas and cultural divisions, and arts and culture. The preparation phase also included each group's creation of an artistic presentation utilizing documentary methodology (e.g. using interviews, photographs, historical documentation, filming, etc.); this emerged and evolved from the locales and the themes being explored.

During the preparation phase each team organized itself according to its goals. An internal coordinator was allocated by $\mathrm{O}$ Teatrão to each group who was responsible for building a unitary sense of team, defining an action plan and building, jointly with his/her group, a set of methodological approaches. The Portuguese team was responsible for central coordination and frequent reports were received giving detailed feedback of what type of activities were being done with the young participants. The type of training developed in each country varied according to the space, questions created, and type of activities that were required. For example, the Portuguese group (like the Italian group) interviewed local residents, business and other local personalities. Participants in the Dutch group created an imaginary character based on the history of their city. They used documentary techniques (like film, video and photography) and historical documents as a starting point to build the characters that represented the Zaanstad's stereotypes. The Belgium group adopted a more experiential methodology through the organization of a series of walking tours, associated with a process of video documentation. In sum, the choices for each specific methodology were based on the question identified by each group (see Table 1) and on the types of artistic and social intervention. In the process, the youth's role in setting the public agenda, defining public priorities, and coming up with effective solutions for specific degraded urban areas was put into action.

\section{Implementation and evaluation/generation of final products}

Implementation consisted mainly of an International Seminar that took place in Portugal in late June/early July 2014, where all the young participants met to share and reflect on their collective experiences of intervention through artistic or 
Table I. Summary of projects per country.

\begin{tabular}{|c|c|c|}
\hline Country & Project description and main question & Methodological focus \\
\hline Belgium & $\begin{array}{l}\text { "The Ringland"-How to build a better } \\
\text { city based on youth's ability to } \\
\text { dream?-Identify possible city trans- } \\
\text { formations through the integration } \\
\text { of youth perspectives }\end{array}$ & $\begin{array}{l}\text { Experiential approach- } \\
\text { self-directed learning } \\
\text { (walking tours), Video } \\
\text { documentation, and visual arts } \\
\text { creative drawing }\end{array}$ \\
\hline Portugal & $\begin{array}{l}\text { "Downtown Mapping"- - How to create } \\
\text { connections between communities } \\
\text { and historical urban areas?-Identify } \\
\text { renovation in historical city areas } \\
\text { through artistic public presentation }\end{array}$ & $\begin{array}{l}\text { Documentary methods and } \\
\text { theater }\end{array}$ \\
\hline Italy & $\begin{array}{l}\text { Me/tamorfosi-how to intervene in } \\
\text { urban spaces and give them new } \\
\text { life?-Intervene in abandoned urban } \\
\text { areas through cultural and artistic } \\
\text { projects }\end{array}$ & $\begin{array}{l}\text { Theater and recollection of local } \\
\text { history + local interviews }\end{array}$ \\
\hline Netherlands & $\begin{array}{l}\text { City Team Project: Divide and } \\
\text { Concur-what would happen if the } \\
\text { Zaanstad villagers had to live } \\
\text { together?-Integrate social and } \\
\text { cultural difference through cultural } \\
\text { practice }\end{array}$ & $\begin{array}{l}\text { Artistic methods } \\
\text { (theater-mime) + individual } \\
\text { reflection + video to create } \\
\text { stereotypes }\end{array}$ \\
\hline
\end{tabular}

cultural activity. The projects presented and shared during the International Seminar are summarized in Table 1.

This Seminar (Figure 1) included non-formal activities like workshops, debates, on site experimental labs, and other non-formal learning experiences. Representatives of each country's partner institution and youth (a total of 30) from the Netherlands, Belgium and Italy came to Coimbra to share their experiences with the Portuguese group. Youth were recruited from among those with fewer opportunities in each partner country. For example, in Portugal, the group was part of the arts education project Bando à Parte, a project for youth in disadvantaged communities, developed since 2010 by O Teatrão. During the seminar, the groups organized themselves by city (Zaanstad, Coimbra, Antwerp and Fabriano) and presented their experiences from their home countries. They then engaged in "Carrousel," an exercise which places the participants in work groups to identify five questions and proposals to solve them. "Carrousel" is an instrument to provide a space for groups to discuss a specific theme, presented from different points of view. After each group shares a question (that is posted in a flip chart sheet) each group is required to provide answers for each question by circulating the flipchart where each question is presented. After all the groups have answered all the questions, a summary of the contributions for each question is made. During 


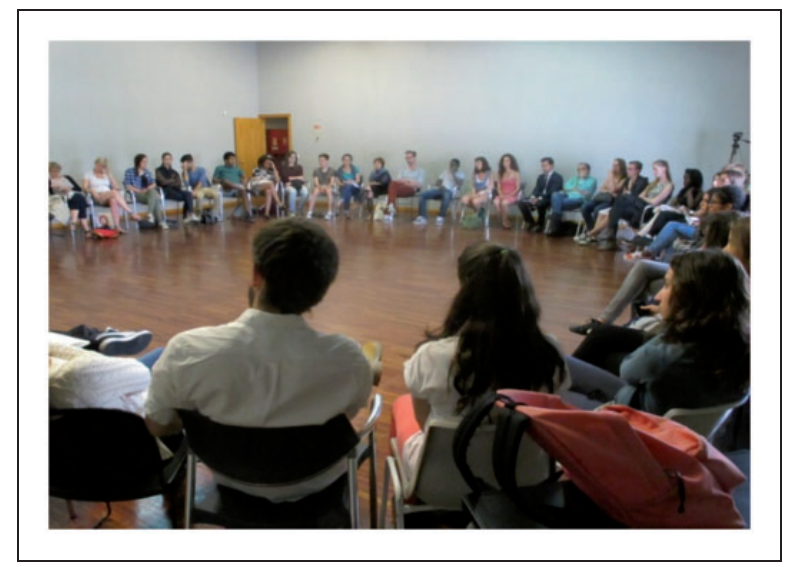

Figure I. Internationl Seminar at $\bigcirc$ Teatrão.

the Carrousel each group agreed on a main question that addressed the problem identified in each city. Politicians, artists, cultural agents, and researchers groups were organized in rotary fashion so that all had the opportunity to bring specific contributions to the different questions. After the working groups and the brainstorming sessions, each group consolidated a structured intervention project for each city/territory, offering a solution for the problem as identified, which was shared and discussed with the participants.

Later in the seminar the youth participated in the joint development of a strategy to elaborate the Youth Policies for Urban Neighborhoods (YPUN) document and final products. The social innovation of YPUN is based on how the methodology combines the joint experience of the youth, policy makers, experts, and artists that come together to define new strategies and policies that may generate social transformation in abandoned urban areas. The participants produced theoretical materials about their national and international experience including the elaboration of the YPUN document. In sum, the approach seeks to create effective political and social impact and generate changes at the national and international levels about the ways youth communities relate to degraded and abandon urban spaces. It also examines how artistic practice can have a direct influence on these locales, stimulating the participation of communities at large in the revitalization of territories. The International Seminar created a space where all these agents came together to reflectively share their methodologies and approaches and jointly create the document YPUN.

\section{Youth involvement in methodological design}

Youth involvement in methodological design varied from context to context, just as locales and spaces of intervention varied from country to country. In Belgium, questions emerged about the lack of connection between youth and urban space- 
spaces with a limited presence of nature and high concentration of pollution. These variables illuminated the need to suggest adoption of spaces for creative reflection about immediate surroundings in schools, and brainstorming intervention projects for urban space. The Portuguese project focused on deepening the youth's knowledge of an historical and degraded urban area of Downtown Coimbra, calling attention to its potential and reflecting, through an artistic presentation that covered the different historical epochs of Salão Brazil, with a view to present and future possibilities of renovation. In Fabriano (Italy), the young participants carried out a theater workshop to reflect on the social and economic changes of their town, seeking to investigate and reconsider the territory they live in as a space for transformation and renewal for the future. They used creative writing, dramatic expression exercises, a documentary approach and a final artistic presentation-created and synthesized by youth-on strategies of intervention in a degraded commercial area. Confronted with the issue of cultural divisions in the city of Zaanstad, the young people from the Netherlands initiated a process of onsite research (which included interviews, videos and site visits), which reframed a new approach to the issue of cultural division in the city and how that could be transcended. Methodologies of the social sciences (interviews, onsite visits and video documentation) were adapted to the process of preparing a video, based on the identified problem.

I now present examples of artistic practice from each project, according to the context of each city/territory and to the problem identified.

\section{Highlights from the AR projects in each of four countries}

\section{The ringland: Creative education and urban transformation in Antwerp (Belgium)}

In Belgium, the inspiring RINGLAND project focused on the highway that surrounds the city of Antwerp, causing a lot of noise pollution. Here, a group of art students was presented with the problems associated with life in the city: general lack of space, lack of green spaces, pollution and noise. Their task was to dream about the future, the city, its space, and how it can be shaped into something fit for everyone.

On a city map of Antwerp, the youth determined how much precious space people would gain if they used all the flat roofs. They could start dreaming from the rooftop of HETPALEIS, their ideal city, or about the future of Antwerp. Then they went out into the city to compare their actual surroundings (both positive and negative aspects). During the International Seminar the youth presented a film they had made during the process, along with two songs that showed both the positive and negative impacts of dreaming. From the youths' point of view it was important to keep an open mind to all the intervention possibilities. Their only constraint was that they make suggestions that could be taken into account by teachers, politicians, and other representatives. They even made a 
song to express their visions about the city: When I grow up, I will tell my children about the bricks; About the pavement that was made as a prison to my soul; A society pushed in a way we hate, but we can't live without it; Building buildings among us so we need to enter rooms we don't want to know (...) You dream about a world you can make your own.

On the other hand, the Belgium group proposed a more subjective, free and creative approach to the arts through the distribution of a "sketch book" to all students. The students would become directly involved in the creation of a final product, through the creation of an individual diary where each student, during the school year, is introduced to a new way of artistic creation and of journal writing. This was done in order to discover new, more personal approaches to creative practice in the visual arts field. Their specific contribution for the final YPUN document was precisely based on how a more structured knowledge of the city can better inform the way young people may think creatively about social and cultural issues; either in relation to the school context or their own city or specific neighborhood.

\section{Downtown mapping in Coimbra: Becoming connected with local history (Portugal)}

In Portugal, the field work took place in collaboration with a cultural programming organization, Jazz ao Centro Clube, situated in Salão Brazil, in the heart of the city of Coimbra. The work developed under this project had as its main focus intervention in the degraded and abandoned downtown area, which, since Medieval times, has been the commercial center of activity of the city, but has entered into sharp decline since 1980. The youth developed their research in the one-hundred-year-old building Salão Brazil, near many stores and always understood as a space of entertainment and accommodation for travelers interested in the new shoe and clothing collections the area had to offer.

The participants applied a documentary methodology, interviewing former residents and merchants: business people who have stayed at Salão Brasil and workers from its different stores. They collected stories, newspaper articles and photographs, covering different time periods, facts and fictions, while challenging themselves to inhabit each of Salão Brasil's floors. They also created scenes that happened in different divisions of the building and a guided visit was offered to the different floors of Salão Brasil, mixing characteristics of different epochs. From the youth's point of view, an urgent social and cultural intervention needed to be made in this part of the city since residents and visitors are disappearing because little or no selfidentification is made with these local assets. "The Baixa is abandoned and no one comes to visit and buy things. Residents are old and students just come here to sleep" (opinion from a young participant in the project). In fact, According to the youth, the fact that part of downtown Coimbra was designated a UNESCO heritage site has no direct significance for the local residents, services, and businesses.

The research and artistic presentation awakened the youth's attention to the power of their action in opening possibilities for urban changes in their own 
communities, having as a starting point the reflection on how young people can actually be more active in the definition of policies for their own cities. A few ideas were shared about how to do this, including the creation of a strategic partnership with schools for the implementation of "open classes" and "workshops" about cultural policy in degraded urban areas and about the different ways in which youth can have an active role in their own city/region. Through the presentation of a public theater intervention, an array of information was created and disseminated, reflecting on the historic development of that area, but also indicating new paths for its renovation. Through fiction, new paths for other functional uses of the urban spaces were presented in the onsite performance. In addition, as the local community was involved in the process of documentary research, specific community-based projects have started to emerge since and a new air and spirit seem to be emerging in this downtown Coimbra area. Some of these projects are the "Há Baixa project", an association of architecture students who designed a strategic plan for the cultural revitalization of the downtown area. Also, the Agency for the Promotion of Baixa de Coimbra (APBC) has developed a set of initiatives with direct implications for businesses, residents, and their connections with tangible and intangible local heritage. The specific contribution for the final YPUN document was based on the definition of specific strategies in the school context (related to the creation of training activities on civic and political culture and to the integration of audiovisual tools as strategies of mediation), that could be implemented at school level and which may have a direct impact on how young students can become politically involved in the issues that affect their own communities.

\section{Me/tamorfosi in abandoned urban areas of Fabriano (Italy)}

For centuries, the town of Fabriano, located not far from the administrative center of the Marche Region, Ancona, has been world famous for its production of exceptional paper for the fine arts, printing, and stationery. Even today Fabriano represents one of the most important industrial areas in Italy. The recent global financial crisis has changed Fabriano's industrial profile and as a consequence the whole panorama of the town has shifted, ushering in several concerns related to desertification and resulting economic and social consequences.

A group of youth from Fabriano's secondary school carried out a theater workshop in order to reflect on the social and economic changes in their town. They based their research on the question of how to intervene in urban spaces and give them new life. They visited many empty spaces in their town and interviewed many people around Fabriano, asking why those places were empty. They also asked what young people can do in order to solve the problems of this crisis. During the Seminar, the participants commented on Fabriano's empty spaces: "Ruins can be everywhere and they hold memories inside, even if we are talking about a shop ruin. That says something about that specific space and its relation to the city as a whole" (an opinion from an Italian youth participant). The youth tried to answer the same questions and created a performance inside one of these spaces. At first, the teenagers 
showed how the frenzy of change has driven men to focus on individual "hyperproductivity", causing them to cease helping one another. They then showed that just having the courage of optimism, making networks, and participating in the social and political life of the city can help people rebuild for the future. After a symbolic funeral of the town, the youth rebuilt everything with a new spirit and a way to rethink the community. In this specific case, the way the final presentation was shared clarified some of the points of view of the young people and their reflection upon the need to locally build partnerships between all types of institutions, even those which are unusual but which together may bring added value (Figure 2). Furthermore, they came to believe that individual entrepreneurship related to local economic and social potential could also become a strategy to ensure a better future for their area.

The concrete result, integrated into the YPUN document, proposes the creation of a self-regulated association of young people that initiates a process of listening to the younger generations in terms of their ideas and perspectives for the future of their space. The incentive for the creation of civic movements, coordinated by young people, was understood as a political strategy that schools and other organizations related to education should defend and try to implement among their students and partners.

\section{Zaanstad city team project: Divide and concur (the Netherlands)}

The city of Zaanstad is a collection of small villages spread out over a distance of about 16 kilometers. Every village has its own identity, history, traditions, and culture, and the people who live there never really leave their towns. The city

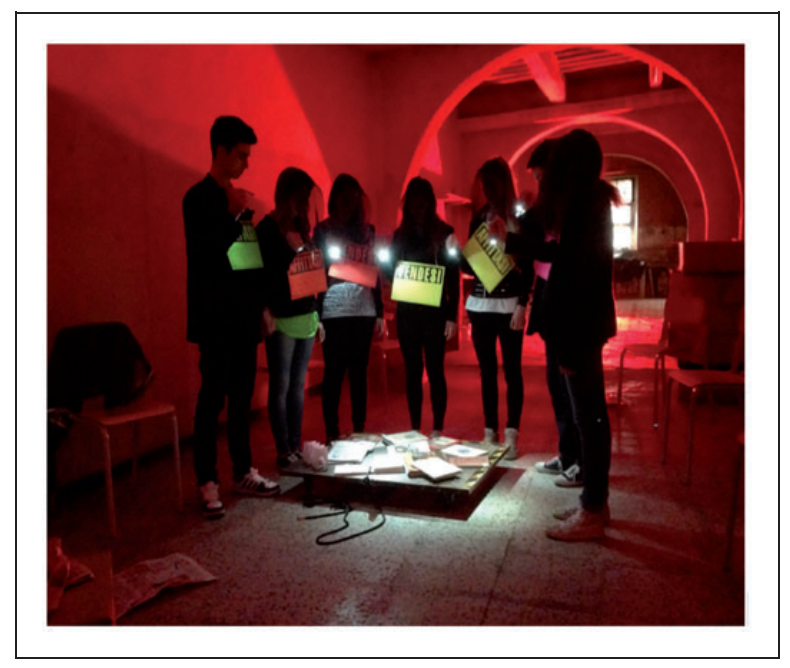

Figure 2. Performance in Fabriano. 
has a rich history related to the industrial revolution of Europe. The invention of the windmill was the most important, as well as the existence of major shipyards. This made the city "the" place to be for ship building, import, and export. As a result of this, Zaanstad is now still in many ways a worker's city. At the same time, it continues to deal with rivalry between the different neighborhoods. The beauty of the city comes from its historic buildings, windmills, and older factories. However, they are scattered and hidden by the newer factories and industry. Currently, the city council is making efforts to "compete" with the very lively city of Amsterdam, by investing in Zaanstad.

The Netherlands' group started from the question of what is the meaning the youth give to the city they live in. They then elaborated on how artistic work could become more visible to all the inhabitants of the city, in order to create a more attractive cultural life, not only for the artists, but all citizens.

Because each youth participant comes from a different village, they built characters based on the preconceptions they have about each other. Some of the participants even expressed their wishes about the city: "it would be good if Zaanstad could have citizens more united with each other. But that is not what is happening" (a comment expressed by one of the youth during the rehearsals). They decided to work on the idea of what would happen if the Zaanstad villagers had to live together. Through improvisations and discussions they came up with different scenes, which culminated in a single performance (Figure 3). All the images, clothing, props, and the scenes came from the presumptions the students had about the different villagers. The storyline that held all the ideas together was the question: can these four villages ever come together? The youth decided to do a play without words to visually express their story. To help the students become more expressive in their body language, they practiced with masks, which could also be used to show both the beauty of the city as well as its less beautiful places. The work was

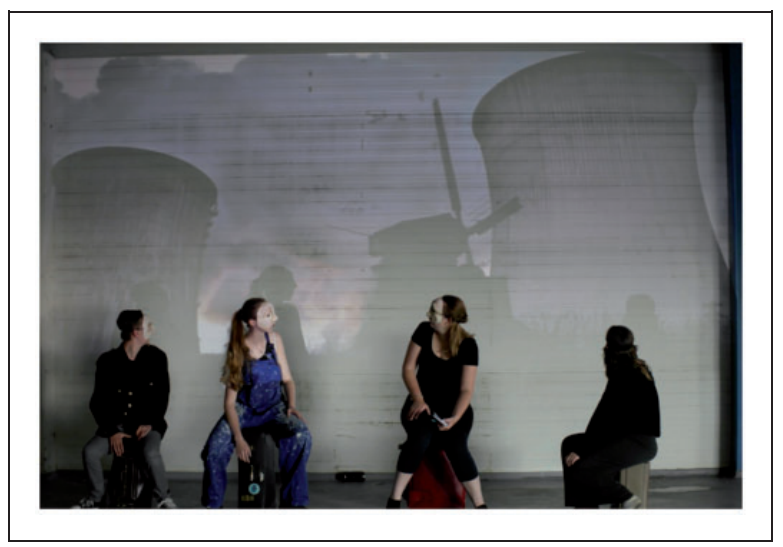

Figure 3. Thetermijn's participants presentation. 
accompanied by video projections the participants made. They were asked to film their favorite places, but also their least favorite ones. This way they made their own diary of the city and showed it to the other participants. In the Netherlands the performance was staged in an old factory, de Honigfabriek, which connects it to the heart of the city.

The overall process required the youth to reflect upon where they actually live, and discuss different possibilities of influencing its transformation, while using instruments and methodologies of the artistic practice. The "City Team Project" included the creation of seven presentations that would take place at the same time during the weekends, creating a dynamic of Urban Festival throughout the city, organized and promoted by young urban artists. The creation of a thematic link established conditions for exposition of the artistic projects from other neighborhoods, promoting audience crossover between inhabitants of the different villages. In terms of the specific contribution to the YPUN document, the youth proposed establishing political conditions for young artists to develop locally, undertaking cultural projects in their own communities that can directly impact their surroundings. They proposed creation of a space in each neighborhood where the young arts creators may develop their own work, securing a direct relation with inhabitants and local communities at large.

\section{Final remarks}

CIUA was presented as an example of how methodologies of cultural and artistic practice can be connected with the involvement of communities within the process of generation of direct intervention in the urban space. I shared how artistic practice can inspire innovative methodologies that can inform and influence the process of action research, and therefore be an innovative force in the field of knowledge production in general. From experiences in four different social and cultural realities, methodologies connected to experiential learning, video documentation, interviews, theater-related methods, and recall of local history have been reinvented by young people as tools to locally intervene in physically, socially, and culturally abandoned areas.

It is however important to clarify the extent to which these young participants engage in PAR locally and analyze how PAR strategies and methodologies create conditions for the enhancement of youth civic knowledge and capacity to intervene, influencing policy and research. The CIUA approach connects theory with practice by generating discussion on challenges and responsibilities of youth to intervene locally in their own cities. Additionally, we created spaces of collaboration and reflection between young people, social scientists, artists, and policy makers, thus bridging missing links between research, practice, and policy.

Particularly important is what we have learnt from the need to articulate AR, the young generations, policy, and research in the field of culture and artistic practice. The experiences presented can contribute to the discussion of the need to create, either under the more formal or the more informal educational curriculum, a context giving younger generations the opportunity to become active in their 
own local communities. In the different countries, this strategy created and developed opportunities for a transversal approach to knowledge generation, one that articulates theory and practice, with a special relevance to civic participation through youth cultural activities. As shown from the experiences presented above, the young participants have taken several types of actions to support their own inquiry processes. They did this by mixing their own perspectives and experiences with innovative methodological procedures that coherently combined methodologies from the social sciences with the arts. In this context, relevance should be given to the focus on the following methodological approaches: experiential learning and self-directed learning, video documentation to support reflective practice, documentary and artistic methods based on theater and reconstruction of local history. The adoption of these types of approaches/methodologies in different youth-related contexts (schools, organizations, among others) should have a direct impact on youth education policies and advance research in the field.

Understanding CIUA as a PAR learning experience requires that we elaborate our concept of "civic engagement", understood its connections with artistic practice and the cultural field. In all the examples, youth groups based their experiments on how the methodologies of artistic practice directly influenced how they became involved civically in transforming the social world. The young participants had different types of onsite immersions in the different communities. These actions used a documentary approach (interviews, photographs, videos) to inform youth action and also as a way of creating, reflecting, and processing knowledge. Another feature of this approach to civic engagement is the fact that, in all the cases presented, the young people involved were challenged to develop a strong and close connection to local aspects of the territory where they were willing to intervene; whether a deepening of the physical (Belgium), historical (Portugal and Italy) or social (Netherlands) relationship to the sites. After this deep local mapping process, a reflection over the materials collected took place so as to organize and assimilate information that was used to create the final artistic products: videos and artistic public presentation. Throughout the process of engagement, the young participants acquired a sense of ownership through all these processes of civic engagement, becoming real stakeholders, direct participants, and agents of transformation.

This proposal is also connected with another contemporary discussion over the growing political disconnection of youth in relation to their surrounding contexts, meaning schools, neighborhoods, cities, and regions. As shown in this paper, the artistic practice in particular and the cultural activity in general offer a range of learning processes that are directly related to the increase of a civic and politically active attitude among youth, generating knowledge on innovative possibilities of articulation. The experiences presented here can represent a starting point for innovative exploration of how artistic intervention projects and artistic inquiry may reframe the way in which PAR can be done at the local level. A second phase of the project could be an exploration of how PAR could be designed and explored at local level, incrementing the participatory engagement of communities. The broad inclusion of the local community in this type of action research projects 
does not represent a main goal of the overall process. However, as the field of participatory action research continues to grow, further research is required in the PAR field and on the contribution of participative involvement of communities through the artistic practice.

\section{Declaration of conflicting interests}

The author(s) declared no potential conflicts of interest with respect to the research, authorship, and/or publication of this article.

\section{Funding}

The author(s) received no financial support for the research, authorship, and/or publication of this article.

\section{References}

Arcidiacono, C., Grimaldi, D., Di Martino, S., \& Procentese, F. (2016). Participatory visual methods in the 'Psychology loves Porta Capuana project'. Action Research, 14(4), 376-392.

Beyes, T., \& Steyaert, C. (2011). The ontological politics of artistic interventions: Implications for performing action research. Action Research, 9(1), 100-115.

Brydon-Miller, M., Antal, A., Friedman, V., \& Wicks, P. (2011). The changing landscape of arts and action research. Action Research, 9(1), 3-11.

Coe, A., Goicolea, I., Hurtig, A., \& San Sebastian, M. (2015). Understanding how young people do activism: Youth strategies on sexual health in Ecuador and Peru. Youth \& Society, 47, 3-28.

Cole, A., Neilsen, L., Knowles, J. G., \& Luciani, T. (Eds). (2004). Provoked by art: Theorizing arts-informed research. Toronto: Backalong Books \& Centre for Arts Informed Research.

De Bruyne, P., \& Gielen, P. (2011). Community arts: The politics of trespassing. Amsterdam: Valiz.

Degarrod, L. N. (2013). Making the unfamiliar personal: Arts-based ethographies as publicengaged ethnographies. Qualitative Research, 13(4), 402-413.

Fisher, K., \& Phelps, R. (2006). Recipe or performing art? Challenging conventions for writing action research theses. Action Research, 4(2), 143-164.

Forster, L., \& Metzger, F. (2015). 'Time Window Weimer': Students map their town's history through augmented reality. Hyperrhiz: New Media Cultures, 12, 1-19.

Guharthakurta, M. (2008). Theatre in participatory action research: Experiences from Bangladesh. In P. Reason, \& H. Bradbury (Eds.), The SAGE handbook of action research: Participatory inquiry and practice (2nd ed., pp. 510-522). London: Sage.

Hess, D. (2009). Controversy in the classroom: The democratic power of discussion. New York, NY: Routledge.

Holtby, A., Klein, K., Cook, K., \& Travers, R. (2015). To be seen or not to be seen: Photovoice, queer and trans youth, and the dilemma of representation. Action Research, 13(4), 317-335.

Kwon, M. W. (2004). One place after another: Site-specific art and locational identity. Boston, MA: MIT Press. 
Levine, P., \& Yourniss, J. (2006). Youth civic engagement: An institutional turn. College Park: University of Maryland.

Lowry, G., Levin, M., \& Tsang, H. (2015). Maraya as visual research. Mapping urban displacement and narrating artistic inquiry. In Duxbury, Garrett-Petts, \& MacLennan (Eds.), Cultural mapping as cultural inquiry (pp. 319-337). New York, NY: Routledge.

Lutkis, A., \& Weiss, A. (2007). The nation's report card: Civics 2006. Washington, DC: National Center for Education Statistics.

Lykes, M. B. (2001). Creative arts and photography in participatory action research in Guatemala. In P. Reason, \& Bradbury (Eds.), Handbook of action research (pp. 363-371). London: Sage.

McDowell, C., \& Otero, V. (2011). Civic organizing through questions: A model for Inclusive engagement. Communities \& Banking, 22(4), 29-31.

McIntosh, H., \& Munoz, M. A. (2009). Predicting civic engagement in urban high school students (Circle Working Paper \#69). The Center for Information and Research on Civic Learning and Engagement, University of Maryland, College Park, MD.

Mediratta, K. (2007). Outside in: Communities in action for school reform. Theory into Practice, 46(3), 194-204.

Mediratta, K., \& Fruchter, N. (2001). Mapping the field of organizing for school improvement: A report on organizing in Baltimore. New York: New York University.

Quintelier, E. (2013). Engaging adolescents in politics: The longitudinal effect of political socialization agents. Youth \& Society, 47, 51-69.

Reason, P., \& Bradbury, H. (Eds). (2001). Handbook of action research: Participative inquiry and practice. Thousand Oaks, CA: Sage.

Schiller, J. (2013). Preparing for democracy: How community-based organizations build civic engagement among urban youth. Urban Education, 48(1), 69-91.

Strand, K., Marullo, S., Cutforth, N., Stoecker, R., \& Donohue, P. (2003). Community based research and higher education: Principles and practices. San Francisco, CA: Jossey-Bass.

Tofteng, D., \& Husted, M. (2011). Theater and action research: How drama can empower action research processes in the field of umemployment. Action Research, 9(1), 27-41.

Warren, M. (2005). Communities and schools: A new view of urban education reform. Harvard Educational Review, 75(2), 133-173.

Westheimer, J., \& Kahne, J. (2004). What kind of citizen? The politics of educating for democracy. American Educational Research Journal, 41(2), 237-269.

Zachary, E., \& Olatoye, S. (2001). A case study: Organizing for school improvement in the South Bronx. New York: New York University.

\section{Author biography}

Claudia P Carvalho, $\mathrm{PhD}$, is a postdoctoral researcher at the Centre for Social Studies, University of Coimbra, Portugal. She is also developing action-research projects in the field of community arts, since 2010, with the professional theater company $\mathrm{O}$ Teatrão. Her research interests include community arts, community participation, participatory governance, cultural mapping, and urban studies in general. 